\title{
Formação de professores da Educação Infantil: ressignificando as práticas docentes por meio de propostas psicocorporais
}

\author{
Early Childhood Education teachers' training: giving \\ new meaning to teaching practices through \\ psychocorporal proposals
} Formación de profesores de educación infantil; dando un nuevo significado a las prácticas docentes a través de propuestas psico-corporales ÂNGELA AdRIANE SCHMIDT BERSCH (Da ELIANE LIMA PISKE(D)

\section{Resumo}

Neste estudo, objetivamos refletir sobre a prática docente por meio de propostas psicocorporais que envolveram o lúdico e suas interfaces. As práticas docentes são aquelas mediadas pelo professor e que, no seu construto, há intencionalidades, promovendo a aprendizagem com sentido e significados. A pesquisa é de cunho qualitativo e, para a análise dos dados, utilizamos a Grounded Theory, aliada ao software Atlas.Ti. As técnicas de intervenção pedagógica aplicadas foram a Psicomotricidade Relacional e as Ginásticas Historiadas. Participaram dos encontros formativos 30 professoras da Educação Infantil do município de Rio Grande/RS. Os instrumentos que geraram os dados foram: observações das

\footnotetext{
a Universidade Federal do Rio Grande (FURG), Rio Grande, RS, Brasil. Doutora em Educação Ambiental, e-mail: angelabersch@gmail.com

b Universidade Federal do Rio Grande (FURG), Rio Grande, RS, Brasil. Mestre em Educação Ambiental, e-mail: e.nanny@hotmail.com
} 
trajetórias que envolvem as atividades psicocorporais, as narrativas das participantes nos memoriais descritivos e no decorrer dos encontros, bem como imagens, filmagens e relatórios oriundos das temáticas das aulas aplicadas aos alunos das professoras. As categorias que emergiram na análise dos dados foram emoções e corpo, evidenciando que o dueto está implicado na comunicação corporal, já que não podemos separar a emoção do corpo, tampouco o corpo da emoção. As narrativas que envolveram as atividades psicocorporais - ou seja, brincar, jogar, criar, atuar, inventar, interagir com o outro e com os objetos disponibilizados - indicaram que são capazes de promover reflexões sobre a formação permanente e uma ressignificação da prática docente.

Palavras-chave: Prática docente. Atividades psicocorporais. Formação de professores. Educação Infantil.

\begin{abstract}
In this study, we aim to reflect on the teaching practice through psychocorporal proposals that involved the ludic and its interfaces. Teaching practices are those mediated by the teacher and, in their construct, there are intentionality, promoting learning with meaning and meanings. The research nature is qualitative and, for data analysis, we used Grounded Theory, together with the Atlas.Ti software. The applied pedagogical intervention techniques were Relational Psychomotricity and Gymnastics Tales. Thirty teachers of Early Childhood Education from the city of Rio Grande / RS participated in the formative meetings. The instruments that generated the data were: the trajectories observations that involve the psychocorporal activities, the narratives of the participants in the descriptive memorials and during the meetings, as well as images, footage and reports from the themes of the classes applied to the teachers' students. The categories that emerged in the data analysis were emotions and body, showing that the duet is involved in bodily communication, since we cannot separate emotion from the body, nor the body from emotion. The narratives that involved psychocorporal activities - meaning, playing, creating, acting, inventing, interacting with others and with the objects available - indicated that they are capable of promoting reflections on permanent training and a new meaning of teaching practice.
\end{abstract}

Keywords: Teaching practice. Psychocorporal activities. Teacher training. Child education.

\title{
Resumen
}

En este estudio, nuestro objetivo es reflexionar sobre la práctica docente a través de propuestas psicocorporales que involucran lo lúdico y sus interfaces. Las prácticas

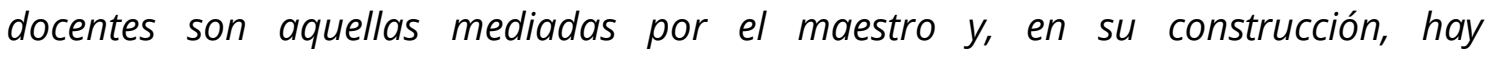
intencionalidades, promoviendo el aprendizaje con significado y significados. La investigación es de naturaleza cualitativa y, para el análisis de datos utilizamos la Teoría Fundamentada, junto con el software Atlas.Ti. Las técnicas de intervención 
pedagógica aplicadas fueron la Psicomotricidad Relacional y Gimnasias Historiadas. Participaron de los encuentros formativos treinta profesoras de Educación Infantil del Municipio de Rio Grande/RS. Los instrumentos que generaron los datos fueron: observaciones de las trayectorias que involucran las actividades psicocorporales, las narraciones de las participantes en los memoriales descriptivos y durante los encuentros, imágenes, filmaciones e informes generados en los temas de las aulas aplicadas a los alumnos y profesoras. Las categorías que surgieron en el análisis de los datos fueron emociones y cuerpo, lo que demuestra que el dúo está involucrado en la comunicación corporal, ya que no podemos separar la emoción del cuerpo, tampoco el cuerpo de la emoción. Las narrativas que involucraban actividades psicocorporales -es decir, jugar, crear, actuar, inventar, interactuar con otros y con los objetos disponiblesindicaron que son capaces de promover reflexiones sobre la formación permanente y un nuevo significado de la práctica docente.

Palabras clave: Práctica docente. Actividades psicocorporales. Formación de profesores. Educación infantil.

\section{Introdução}

Articular o lúdico e suas múltiplas possibilidades por meio de atividades psicocorporais na formação de professores da Educação Infantil para refletir sobre as práticas docentes é o objetivo do artigo. Quando nos referimos ao lúdico, estão implícitos seus diversos desdobramentos, como a brincadeira, o brinquedo, o brincar e o jogo - termos que, embora tenham conceitos e significados distintos, remetem ao que há de mais significativo para as crianças, que é o ato de interagir, de experienciar, de relacionar-se consigo, com os outros e com os objetos e símbolos presentes no contexto (GARCIA; BERSCH, 2019). Neste estudo, o termo crianças está articulado a infâncias, que, por sua vez, reflete um conceito histórico-cultural que decorre da educação.

O entendimento de infâncias que temos hoje tem um construto articulado a uma história, a uma cultura e a uma sociedade que sofreu modificações. Se no passado a criança era considerada um adulto em miniatura, sem linguagem e, portanto, praticamente invisível (ARIÈS, 1978), atualmente é produtora e autora de culturas (SARMENTO, 2002). Conforme Sarmento (2002) nos explica, crianças sempre existiram, porém, as infâncias são uma invenção da modernidade.

$\mathrm{O}$ conceito de infâncias vem sofrendo modificações e se ajustando às demandas sociais, culturais, políticas e econômicas, em consonância com a 
formação permanente. Vale lembrar que a formação de professores de Educação Infantil se intensificou a partir de 1990 no âmbito das políticas educacionais e nos espaços acadêmicos (FLÔR; DURLI, 2012). Embora o histórico da formação de professores não seja o foco deste trabalho, é relevante trazer à tona que foram muitas discussões e debates sobre a temática. Analisando as produções que atualmente temos na área da Educação Infantil e suas múltiplas interfaces, as conquistas são significativas.

As Diretrizes Curriculares Nacionais para a Educação Básica (BRASIL, 2013) bem como as Diretrizes Curriculares Nacionais para a Educação Infantil (BRASIL, 2010) destacam a relevância das brincadeiras e da interação, entre outros aspectos, para a proposta pedagógica para a Educação Infantil. Este estudo, portanto, está consonante com a legislação vigente, que orienta os processos pedagógicos nas instituições educacionais.

Essas compreensões e esclarecimentos são cruciais em momentos de formação de professores. É imprescindível que o professor tenha conhecimentos dessas mudanças históricas e, especialmente, das concepções que são/estão vigentes atualmente no que tange a crianças e infâncias. Abordar esse tema significa falar de brincadeiras, do brincar e dos seus desdobramentos lúdicos, aspectos inerentes às práticas docentes no cotidiano da Educação Infantil. Franco (2016) esclarece que há práticas docentes de cunho pedagógico e aquelas sem a perspectiva pedagógica esta última desconsidera a construção do humano. Portanto, consideramos práticas docentes aquelas que são mediadas pelo professor, quando há intencionalidades em sua práxis, havendo a atribuição de sentido e significado.

Será prática pedagógica quando incorporar a reflexão contínua e coletiva, de forma a assegurar que a intencionalidade proposta é disponibilizada a todos; será pedagógica à medida que buscar a construção de práticas que garantam que os encaminhamentos propostos pelas intencionalidades possam ser realizados (FRANCO, 2016, p. 536).

A proposta deste estudo é apontar algumas possibilidades de orientar o professor, em momentos de formação, a interagir com as crianças em seu contexto de aprender, ou seja, em todos os espaços da escola. Para tanto, nos utilizamos de duas estratégias de intervenção pedagógica que consideramos profícuas na 
comunicação entre professores e crianças: Psicomotricidade Relacional e Ginástica Historiada. Nesse ínterim, o artigo está dividido em quatro momentos: inicialmente, vamos destacar a importância da comunicação corporal, posteriormente, a metodologia, seguida dos resultados e das considerações finais.

\section{Comunicação Corporal: narrativas por meio da linguagem do corpo}

Por que estamos destacando a comunicação corporal? Entendemos que a linguagem corporal é a primeira e a mais natural forma de comunicação entre as pessoas. Se nos reportarmos especificamente às crianças, quanto mais tenra sua idade, maior será essa comunicação pela via corporal - a qual se dá por meio de gestos, posturas, sons, expressões faciais, formas de se deslocar e movimentar. Por intermédio desses movimentos, podemos compreender as emoções e os sentimentos, como medo, insegurança, alegria, contentamentos, satisfações e outros desejos e necessidades comunicados pelas crianças. Por isso, reiteramos que o olhar do professor a esses manifestos é fundamental (BERSCH; PISKE, 2020).

Outro aspecto crucial no processo de formação de professores com atividades que envolvem vivências psicocorporais é a observação do docente que está coordenando a atividade formativa. O profissional deve adotar uma postura de escuta e de observação da trajetória dos participantes (NEGRINE, 1995; BERSCH; PISKE, 2020). É preciso observar os movimentos corporais, as construções concretas e simbólicas elaboradas, as interações com o(s) outro(s) e os objetos disponibilizados no espaço. Essa ação de olhar atento deve ser pautada nos encontros para que os participantes também a adotem nos seus espaços educacionais.

O professor, por diversas razões, esquece que esse corpo é relacional e deve ser entendido em sua totalidade, jamais segmentado em padrões motores, psicossociais, cognitivos. Melucci (2004) afirma que ninguém pode dizer o que sentimos em nosso corpo; cada um de nós é o único que pode falar de si mesmo, usando o próprio corpo. O autor relembra Merleau-Ponty (1994), que subsidia essa linha de raciocínio quando trata da realidade vivida e percebida que passa por meio 
do corpo, questionando: de que forma vamos compreender o corpo do outro se não entendermos primeiro o nosso?

Entendemos que não há uma ordem, mas uma prioridade, ou seja, a compreensão de si passa pela compreensão do outro, mas não que esta se sobreponha. O processo de compreensão de si é dinâmico e constante. Também é evidente que não é possível fragmentar ou subdividir os sujeitos: pelo contrário, o que desejamos é a compreensão da unidade, da totalidade. Por isso, a experiência formativa é fundamental.

Tardif (2005) esclarece que os saberes dos professores advêm de uma diversidade de espaços e tempos com os quais tem interação, como por exemplo: família, escola, igreja, etc. $O$ autor explica que os saberes docentes não se constituem somente a partir das instituições de formação como a universidade, mas de uma gama ou amálgama advindo das experiências de vida. Nesse sentido, os saberes dos professores advêm de vivências e experiências pessoais, da formação em diferentes níveis de ensino, como educação básica, graduação, pós-graduação. Portanto, essa combinação ou fusão de saberes articulados e interconectados se concretiza e se (re)significa nas interações pedagógicas com as crianças.

Corsaro (2011) explica que as crianças não são meros reprodutores ou internalizadores da cultura adulta. Ao cunhar o termo "reprodução interpretativa", sugere:

O termo interpretativo abrange os aspectos inovadores e criativos da participação infantil na sociedade. [...] já o termo reprodução [...] inclui a ideia de que as crianças não se limitam a internalizar a sociedade e a cultura, mas contribuem ativamente para a produção e mudança culturais(CORSARO, 2011, p.31).

As crianças, portanto, têm uma maneira singular de significar o mundo e as coisas por intermédio de um sistema simbólico que inclui a estrutura cultural e social - e o fazem por meio do brincar e da ludicidade. Com isso, afirmamos que os aspectos supracitados apontam que as crianças são atores sociais e protagonistas, seres que interpretam as culturas dos adultos de forma simbólica e que interagem com o meio social, apropriando-se e produzindo saberes inerentes ao meio (SARMENTO, 2002; SARMENTO; GOUVEA, 2009). 
Para que o professor seja sensível a esses aspectos, é imprescindível que ele os vivencie por meio de seu próprio corpo e junto com as crianças. As práticas docentes no âmbito da Educação Infantil devem considerar a escuta e a observação, levando em conta que o corpo comunica, expressa, manifesta sentimentos e emoções, sendo constituído de muitas narrativas. As autoras Moutinho e De Conti (2016) esclarecem que, ao serem estudadas, as narrativas devem considerar as subjetividades das pessoas, as suas experiências, a construção de sentidos, em determinado tempo e espaço. Para este trabalho, tomaremos como foco os momentos formativos com os professores da Educação Infantil, além de suas práticas docentes nos espaços escolares com as crianças.

Nesse sentido, no decorrer dos encontros de formação ${ }^{1}$, os participantes tiveram a oportunidade de experienciar ao comunicar e atribuir sentido na narração de suas vivências. Por falar nos saberes da comunicação corporal, evidenciamos a base metodológica adotada no estudo.

\section{Metodologia}

A pesquisa configura-se em qualitativa e pesquisa-intervenção (ROCHA; AGUIAR, 2003). O estudo segue as orientações da Resolução n 466, de 12 de dezembro de 2012, do Conselho Nacional de Saúde e demais determinações do Comitê $^{2}$ de Ética em Pesquisa na área da saúde da Universidade Federal do Rio Grande - FURG.

Participaram deste estudo 30 professoras que atuam na rede municipal de Educação Infantil. Para fins de análise de dados e assegurar o anonimato, vamos considerar o código P como professora e o número de 1 a 30 referindo-se aos participantes. Foram 14 encontros entre abril e agosto de 2019. Desse total, as temáticas foco deste texto, Psicomotricidade Relacional e Ginástica Historiada, representaram 6 encontros. Cada encontro tinha a duração de 2 horas.

\footnotetext{
${ }^{1}$ Estes momentos serão descritos detalhadamente na metodologia.

2 Informações disponíveis em: https://cepas.furg.br/
} 
Os encontros aconteceram em uma sala da FURG. A opção por esse espaço se deu devido à localização da instituição (facilitando o acesso aos participantes) e às condições do ambiente (o chão da sala era de tatame e o amplo espaço era propício para as atividades propostas).

Os professores responsáveis pela formação eram docentes da instituição ou doutorandos de programas de pós-graduação da universidade. O planejamento das atividades foi realizado no coletivo para que houvesse uma coesão e coerência didático-pedagógica na proposta.

Para as atividades de Psicomotricidade Relacional (PR), foram utilizados materiais não estruturados ${ }^{3}$, como tecidos de diversos tamanhos e cores, cordas, jornais, tampas, tampinhas, bastões de madeira de diversos tamanhos e espessuras, cones, arcos e som.

Nas Ginásticas Historiadas $(\mathrm{GH})$, os materiais não estruturados também podem fazer parte do repertório vivencial, além de envolverem as múltiplas linguagens. Sendo assim, as Ginásticas Historiadas e a Psicomotricidade Reacional são metodologias associativas. Neste momento, salientamos sobre as Ginásticas Historiadas: como o próprio termo sugere, são contações que envolvem o movimento corporal (PISKE; FIGUEIREDO; MARQUES, 2019). Nas Ginásticas Historiadas, os gestos são imprescindíveis, estimulando as expressões por meio das mãos e do corpo.

Inicialmente, explicamos sobre a proposta, como serão as Ginásticas Historiadas, quais materiais não estruturados utilizamos e definimos que serão apenas os gestos que farão parte. Além disso, explicamos sobre o espaço físico que será utilizado, o qual pode estar representado pelos tapetes, por cordas e/ou outros objetos combinados anteriormente com os participantes. A ginástica historiada vai se construindo com cuidado e com a conversa estabelecida vivencialmente. A GH está em consonância com a PR; ambas mobilizam o corpo em movimento com as múltiplas expressões. A comunicação afetiva das duas práticas psicocorporais tem como base as relações consigo e com os outros, além das implicações da afetividade.

${ }^{3}$ Os materiais não estruturados são objetos que as crianças (re)significam a partir da imaginação, por exemplo: cabos de vassouras que se tornam cavalos; cones em chapéus; caixas de papelão em carros, cabanas etc. 
A Psicomotricidade Relacional enfatiza, em sua estrutura metodológica, a escuta de si e dos outros, a comunicação entre o corpo e os aspectos psíquicos e psicoafetivos dos envolvidos. A PR oportuniza o jogo e o movimento espontâneo, estimulando os participantes a expressar suas dificuldades relacionais, os desejos, as angústias, as necessidades e uma gama de emoções e sentimentos que são potencializados por meio da socialização e comunicação relacional consigo mesmo, com o(s) outro(s), com os objetos e símbolos presentes no espaço e nas atividades propostas pelo professor (JULIANO et al., 2016, BERSCH; PISKE, 2020).

Nessa linha reflexiva, esclarecemos que a PR tem como eixo a comunicação, a exploração corporal e as vivências simbólicas (NEGRINE, 1995). Contudo, a escolha dos materiais a serem disponibilizados será do professor, e isso poderá alavancar e conduzir a prática psicomotriz para um caminho ou outro (LIMA; PISKE; BERSCH, 2018). Tal escolha não é casuística, ela deve ser oriunda de observações e análises efetuadas nos comportamentos e trajetórias do brincar das crianças no decorrer das sessões. Os encontros de PR são denominados de sessões (NEGRINE, 1995; LAPIERRE; LAPIERRE, 2010) e se estruturam dessa forma:

a) Rito de entrada: momento em que são feitas as combinações sobre regras e atividades que acontecerão no decorrer do encontro, a fim de favorecer a comunicação entre os participantes.

b) Sessão propriamente dita: o professor, por intermédio da disponibilidade de materiais e de sugestões de atividades, pode mobilizar os participantes tanto de forma individual como coletiva.

c) Sensibilização e volta à calma: é o momento em que o participante relaxa e reflete sobre o que realizou na sessão. Aqui, é possível utilizar o som, massagem ou outras estratégias que favoreçam a volta à calma, bem como a reflexão sobre as atividades e sensações percebidas no decorrer da sessão.

d) Rito de saída: espaço-tempo que oportuniza aos participantes comentários sobre as criações, vivências, além de ser um momento para a escuta da prática psicomotriz dos demais envolvidos.

A PR, técnica de intervenção pedagógica, oportuniza uma atitude ativa dos participantes por meio de atividades lúdicas e jogos simbólicos em um ambiente 
seguro e prazeroso, o qual é acompanhado por um ou mais professores. Evidenciamos que a tônica corporal ocupa lugar privilegiado nas sessões, pois permite diversas possibilidades a serem exploradas ao interagir consigo, com o outro e com os objetos e símbolos presentes ou criados no espaço (JULIANO; BERSCH, 2016, LIMA; PISKE; BERSCH, 2018).

É saudável a repetição dos gestos com prazer: as características das Ginásticas Historiadas são marcadas pelos jogos simbólicos, as construções e as regularidades vivenciadas nos exercícios de faz de conta são desencadeadoras das construções simbólicas (sentir o cheiro da terra molhada, brincar de casinha e outros). Estas ações realizadas pelas crianças se caracterizam por estarem relacionadas aos contextos das crianças e têm como base os elementos concretos presentes em suas vidas e rotinas, como nos objetos de casa, da escola, nos brinquedos, nos livros, nos materiais, nas ferramentas e nas tecnologias, bem como nos elementos simbólicos que se encontram ou são construídos junto às famílias, às culturas (BARBOSA, 2014).

Por meio da imaginação e da criação na $\mathrm{GH}$, os participantes podem se transformar num guerreiro, numa bruxa, num macaco e os objetos podem ter outras funções — o importante é mergulhar na vivência de maneira experiencial do corpo em movimento, havendo a possibilidade da criação das práticas psicocorporais (PISKE; BERSCH, 2019). O lugar do lúdico nessa etapa é importante, sendo necessário manter o espaço das vivências, do faz de conta e das descobertas ao (re)significar as Ginásticas Historiadas como repertórios necessários para a Educação Infantil. Sendo assim, tanto a PR quanto as GH relacionam os aspectos psicocorporais, cognitivos e afetivos para o bem-estar do ser humano, já que podem proporcionar limite, autonomia, cuidado, cooperação, observação e demais elementos fundamentais na formação dos professores de Educação Infantil.

A estrutura pedagógica tanto da Psicomotricidade Relacional como da Ginástica Historiada seguiu alguns ordenamentos: iniciávamos as atividades em roda, com a apresentação dos envolvidos e da proposta a ser desenvolvida naquele encontro; na sequência, o professor formador orientava os participantes quanto às atividades e estes as desenvolviam com o corpo em movimento (lembrando que a tônica das tarefas envolve a comunicação corporal e as relações dos professores 
consigo, com os objetos disponibilizados e os símbolos); logo após, todos nos reuníamos novamente em círculo e, com subsídio de um texto teórico sugerido previamente pelo docente, fazia-se a discussão sobre as possíveis articulações e possibilidades para a sala de aula na atuação das professoras com as crianças.

Importante destacar que, ao final dos encontros, os participantes elaboravam um memorial descritivo no qual registravam as principais emoções, descobertas, (in)certezas, dúvidas etc. que emergiram durante as atividades. Para o último dia, criaram um registro em forma de vídeo ou fotografia digital, que denominamos de feedback. Esse recurso se referia à aplicação de alguma atividade com a turma em que a professora atuava em sua escola, inspirada na atividade que havia sido proposta pelo docente. A proposição era levar dinâmicas que pudessem inspirar os participantes e, desse modo, recriar e adaptar para seu contexto e sua realidade.

As apresentações do feedback de cada professora participante se deram por meio da oralidade, imagens, filmagens/vídeos das suas aulas com seus alunos e um relatório. Nele, a professora deveria relatar as dificuldades e facilidades que emergiram no decorrer da sua interação com a turma, a partir da aula inspirada em alguma temática sugerida e vivenciada por ela na formação de professores.

Portanto, para a geração dos dados, utilizamos memoriais descritivos dos professores, observações dos docentes durante a trajetória e comportamento dos educadores no decorrer dos encontros. Também foram utilizados vídeos / filmagens, fotos e relatórios dos professores sobre as aulas com seus alunos.

A pesquisa trata de uma abordagem qualitativa e, para sistematizar a gama de dados gerados, utilizamos a Grounded Theory (STRAUSS; CORBIN, 2012) e o software Atlas.Ti (SAN MARTÍN, 2014; ARIZZA et al., 2015; PISKE et al., 2018) para a análise das informações. Esses recursos auxiliaram os pesquisadores a fazer os dados e informações relevantes emergirem. A Grounded Theory, por meio do seu rigor metodológico, oportuniza ao pesquisador, em princípio, a compreensão do mundo de seus participantes, ou seja, perceber a perspectiva pessoal deles (GLASER; STRAUSS, 1967; CHARMAZ, 2009). 
A análise dos dados é um momento singular no processo da pesquisa, sobretudo quando o pesquisador percebe o surgimento de categorias significativas que refletem o seu objeto de estudo. Nesse caso, as categorias mais potentes e consolidadas são emoções e corpo.

Com os dados analisados, as emoções e o corpo foram reflexos das compreensões a partir das narrativas que emergiram nas relações no decorrer dos encontros formativos de professores da Educação Infantil: "as relações sempre estão mudando, e o desafio se impõe toda vez, de novo e de novo. Para os indivíduos, a necessidade de trabalhar conscientemente em suas relações mútuas nunca acaba" (ELIAS, 2012, p. 493).

Nesse sentido, iniciamos os resultados com uma informação que chama a atenção e nos possibilita evidenciar as duas categorias, sendo que não há emoções sem a presença do corpo e tampouco a vivência corporal sem emoção. O dueto elementar está implicado na comunicação corporal, já que não podemos separar a emoção do corpo e/ou o corpo da emoção: segundo Maturana e Varela (2011), esses dois elementos envolvem o linguajar.

Iniciaremos a apresentação dos dados pela categoria emoções. As informações referentes às narrativas, às falas ou à escrita dos envolvidos serão apresentadas em itálico. Excertos referentes às filmagens e fotos também serão identificados e, quando tratarem da fala de algum participante, também estarão em itálico.

As estratégias pedagógicas utilizadas nos encontros por via da Psicomotricidade Relacional e das Ginásticas Historiadas propiciaram aos participantes uma gama de informações, experiências, vivências e narrativas que extrapolaram o tempo e espaço da formação. Foram fontes inspiradoras de outros momentos e de experiências oportunizadas pelas professoras participantes em suas práticas docentes na interação com seus alunos. Contudo, a autopercepção das emoções que as vivências no espaço e tempo dos encontros formativos provocaram foram muito significativas, pois refletem possivelmente naquilo que seus alunos ou seja, as crianças — poderão sentir quando tais atividades lhes forem propiciadas.

Umas das potencialidades da PR é oportunizar que os envolvidos possam passar de uma situação passiva diante da atividade para uma outra ativa. Nessa nova 
condição e a partir da interação consigo mesmo, com o(s) outro(s) ou com os objetos e símbolos presentes no contexto, o participante poderá aprimorar aprendizagens psicomotoras e o desenvolvimento biopsicossocial.

Seguindo por esse viés, podemos considerar tal cenário

como uma possibilidade de crescimento pessoal, de ajuda mútua e estratégias relacionais que podem oportunizar um espaço de reflexão sobre sua própria prática e seus anseios, suas aflições, seus fantasmas, dentre outros elementos de interferência psíquica negativa(BERSCH; PISKE, 2019).

A estrutura dos encontros objetivava a reflexão sobre a prática docente, as possibilidades de desconstrução de algumas crenças, a descristalização de algumas certezas e a mobilização do professor pela via psicocorporal (PISKE; BERSCH, 2019). A narrativa ${ }^{4}$ de uma das professoras no rito de saída do segundo encontro elucida esse sentimento:

Raramente eu brinco com as crianças, assim de forma verdadeira, normalmente eu oriento e coordeno a brincadeira ou a atividade que eu proponho, mas não chego a me divertir com ou como elas. Aqui interagindo com as colegas e com os materiais que a professora trouxe eu consegui me divertir muito e tive uma noção de como as crianças se sentem nos momentos de brincar, especialmente quando ele é de livre escolha delas(P.17).

Outros excertos extraídos dos memoriais descritivos no primeiro encontro também evidenciam as emoções com relação as vivências:

Penso que havia em mim um turbilhão de emoções, muito além do que consegui relatar, pois vivenciamos momentos tão prazerosos, que já fazem parte do nosso cotidiano, mas de maneira diferente, foi a "nossa" vez de experenciar e se permitir experimentar, de perceber o quanto é difícil falar para um público diferente, de se questionar por que ainda temos escolas que não valorizam as construções das crianças, não respeitam sua criatividade e não compreendem o quanto a ludicidade possibilita a construção de conhecimentos significativos(P.10).

A função do teatro foi particularmente um momento de livre expressão, deleite, renovação, relaxamento, comunicação, muitas risadas, enfim, de consciência e celebração da vida no seu amplo sentido (P.05).

\footnotetext{
${ }^{4}$ As narrativas foram transcritas na íntegra sem modificações para manter a originalidade da autoria.
} 
A PR, por meio da sua estrutura, pode oportunizar o exercício do planejamento, a organização das ideias, a elaboração e desenvolvimento de atividades concretas e simbólicas, além de potencializar vivências psicocorporais plurais e a interação individual ou coletiva (LAPIERRE; LAPIERRE, 2010; NEGRINE, 1995; BERSCH; PISKE, 2020). Também pudemos verificar um exemplo desse contexto na escrita em um dos relatórios:

Diante do envolvimento e participação das crianças, penso que essa é uma atividade muito válida para trabalhar com as crianças. É uma oportunidade de desenvolver a criatividade, o senso de planejamento, trabalhar a coordenação motora e fazer com que eles percebam que podemos nos divertir com materiais acessíveis a todos. Enfim, as crianças ficaram muito felizes e se divertiram muito, mostrando um espírito de colaboração, ajudando e convidando os colegas para brincarem (P.09).

As práticas psicomotoras, por meio da PR e das GH, estimulam a criatividade, a interação, a sensibilização do participante para consigo e para o(s) outro(s) (SÁNCHEZ; MARTÍNEZ; PEÑALVER, 2003). Embora as atividades aconteçam na coletividade, as elaborações sobre suas emoções, seus conflitos, desejos, suas angústias, necessidades etc. são de ordem individual (BERSCH et al., 2019). Esse misto de sentimentos e emoções fica claro nas contribuições e narrativas de duas participantes, ao final do segundo encontro:

Nesta aula foi possível vivenciar diversos sentimentos, sendo o primeiro a curiosidade $e$ a angústia quando foi disposto no meio da roda diversos materiais, como bambolês, cones, corda, etc; e ficamos imaginando o que faríamos com tais materiais. Logo, podemos colocar a criatividade em prática, manuseando os materiais e criando possibilidades de atividades, brincadeiras, jogos. Foi um momento bastante rico, onde deixamos um pouco de ser professoras para nos colocarmos no lugar de alunos e poder imaginar e inventar. Além disso, podemos trocar ideias e ampliar nosso repertório para levar às crianças. (P.23)

No início eu estava sofrendo, pois tenho muita vergonha de me expor diante de outras pessoas, queria que aquela atividade passasse logo (...). Mas, no final, me senti muito bem, porque consegui superar aquela angústia do início do encontro (P.13).

O exercício da observação é crucial. O docente, na condição de coordenador da atividade, deve acompanhar os movimentos, gestos, construções, narrativas e elaborações dos participantes. Olhar, observar, escutar e acompanhar a trajetória dos envolvidos são etapas imprescindíveis para a elaboração de feedback e planejamento do encontro seguinte. Isso pode contribuir para minimizar, sanar ou 
refletir sobre os possíveis conflitos e emoções que possam ocorrer com seus alunos (MASETTO, 2003; CARVALHO; WAGNER; QUITETE, 2013).

Foram 2 horas de muita interação e alegria! Essa é a palavra que define esse momento. Sinto enorme prazer ao me divertir com as colegas e, principalmente, por voltar a ser criança, reviver as brincadeiras da minha infância e levar para as minhas crianças essas experiências (P.14).

Foi uma noite em que voltamos a ser criança através das brincadeiras e jogos que realizamos. Como é bom colocar-se no lugar do outro e perceber o quanto nossas aulas podem fazer a diferença na vida dos nossos alunos. As aulas cheias de alegria e motivação fazem a diferença. Foi uma noite onde pudemos compartilhar os saberes $e$ ainda aprender outros, além de muita diversão (P.16).

Os relatos acima se referem aos memoriais descritivos ao final de um encontro de formação, e ecoam os sentimentos e emoções das professoras com relação à atividade proposta. Vivenciar as atividades que tenham como tônica o corpo e a mente como unidade reflete numa aprendizagem mais significativa e as motiva a oportunizar aos seus alunos, nas suas escolas, experiências semelhantes, oportunizando a reflexão sobre a sua prática docente.

A dinâmica realizada em nosso primeiro encontro trouxe uma série de sentimentos a possibilidade da descontração, ansiedade para desfrutar dos materiais, e a mente borbulhando imaginando como as crianças na sala se posicionariam. Nos faz pensar sobre atividades de um planejamento sem o "ensinar" a pensar o que fazer, sendo diferente de dizer o que fazer. Dar a criança a autonomia de perceber-se como condutora da sua atividade livre para ser o que ela realmente planejou fazer. Durante a prática os materiais nos conduziam aos mais diversos movimentos e criações percebendo o quanto a imaginação e criação são estimulados por materiais não estruturados (P.28).

O relato da professora corrobora com a afirmação de Sarmento (2002) e Corsaro (2011), quando se referem ao protagonismo e à autoria da criança nas suas elaborações e construções. Reiteramos a importância de o professor considerar, em suas práticas docentes, a implicação das vivências psicocorporais para potencializar a comunicação, a expressão e a manifestação das subjetividades na construção das aprendizagens. 


\section{Corpos: o que ecoam ou ressoam?}

Outra categoria que emergiu na análise dos dados refere-se às questões do corpo e suas interfaces. Acreditamos que tal categoria tenha emergido em decorrência da linguagem corporal, que foi uma constante nos encontros formativos. Enquanto grupo docente e responsáveis pela formação, apostamos na expressão e mediação pela via corporal como uma potente estratégia de mobilização de conceitos, posturas, valores que pautam nossas práticas docentes. Tardif e Lessard (2005), em estudos sobre saberes e formação docente, alertam para a importância da linguagem corporal e de sua implicação no processo de comunicação interpessoal.

Partimos do princípio de que, antes de trabalhar com o outro, é imprescindível o autoconhecimento, especialmente por meio da corporeidade, propiciando uma nova via de impressão e expressão. Para explicar o termo corporeidade, citamos Merleau-Ponty (1994), o qual considera o corpo como sendo o ponto de vista sobre o mundo. É por meio do corpo que o ser humano se conhece e se reconhece no mundo, considerando também a percepção da objetividade e da subjetividade. Nesse sentido o corpo é o organismo de inter e intra relação, de reflexão e narrativas sobre o contexto que está inserido e sobre si próprio.

A cultura influencia e impacta a percepção da pessoa sobre os fenômenos. Embora a estrutura biológica dos seres humanos seja muito semelhante, a visão de/do mundo o torna distinto dos demais. Nessa lógica a percepção do corpo e da corporeidade é social e culturalmente construída e caracteriza a pessoa como singular, já que é constituída por meio das vivências e experiências pessoais (MERLEAU-PONTY, 1994).

Seguindo por esse caminho, Elias, ao abordar a questão dos impulsos emocionais que são comunicados pelas pessoas por meio do corpo, afirma que "as emoções e os movimentos a ela relacionados têm uma função dentro do contexto de relacionamento entre as pessoas" (ELIAS, 2009, p. 46). Contudo, discussões e reflexões sobre o corpo e sua comunicabilidade têm pouco espaço nos processos formativos - no entanto, neste estudo, elas foram o foco. 
Realizar esse curso é, para mim, a possibilidade de trazer para minha prática docente momentos que explorem a corporeidade de forma mais lúdica e eficaz. Essa é uma linguagem da qual eu ainda tenho várias limitações(P.06).

A última prática significou a percepção do meu próprio corpo, pois, às vezes, me encontro no "modo automático", sem sentir. Além da troca de afeto e da sensação de paz que esta proporcionou (P.11).

As narrativas acima dizem respeito à escrita do memorial descritivo de duas professoras ao final de um encontro, e ressoam a importância de utilizar estratégias de intervenções pedagógicas que se utilizam de vivências corporais como mecanismo de intervenção e interação. Como justificar aos professores que o brincar, o movimento, a linguagem corporal, a interação, a expressão etc. são imprescindíveis no processo de ensino e aprendizagem? Como traduzir em palavras as emoções e sentimentos que as vivências psicocorporais provocam nos professores participantes e também nas crianças? Esses são alguns dos questionamentos elaborados pela equipe docente no momento de planejamento das atividades nos encontros de formação das professoras. Para tais questões, as respostas foram unânimes: pela vivência corporal, intervenções e interações dos praticantes.

É impressionante as possibilidades e as potencialidades do corpo e da linguagem corporal. Trabalhos muito movimentados e ações, cuidados e o envolvimento da turma foi pleno. Correram, pularam, saltaram, trocaram entre si e no final todas as crianças estavam bem cansadas, mas sorridentes e felizes(P.20).

Penso sobre o quanto as crianças podem se beneficiar destas práticas nas quais, o principal instrumento é o próprio corpo e deste, a percepção de respeito, afeto e novas possibilidades(P.05).

As experiências e vivências que envolvem o corpo propiciam para a criança a aprendizagem de diversos aspetos: possibilidades e limites de cada movimento; a expressividade sem padrões; a valorização de seu corpo e o dos colegas. A linguagem corporal oportuniza para a criança não somente o desenvolvimento das capacidades físicas, mas também cognitivas, sociais e afetivas (SAYÃO, 2002).

As falas das professoras no rito final de um encontro reiteram a afirmação acima: 
Sou conhecida com a prof. do movimento na escola, por pensar que este é fundamental no desenvolvimento das crianças desde os primeiros anos de vida é mais que o simples deslocamento do corpo, constitui uma linguagem que permite que as crianças se expressem através da dança, músicas, ritmos, coreografias e tenham um pleno desenvolvimento cognitivo, motor e sociocultural psicomotor, facilitando no processo de construção da aprendizagem(P.26).

Para mim a Educação Infantil é brincar, é movimento, é corpo e tudo isso é educação (P.07).

$\mathrm{Na}$ infância, especialmente na Educação Infantil, as crianças precisam experimentar e vivenciar múltiplas e diversas atividades motoras. Tal ação, explica Falkenbach (2005), promove a ampliação do vocabulário motriz, o que favorece o despertar de experiências psicomotoras que progressivamente se ampliam para níveis de competência cada vez mais complexos.

A prática docente, bem como a vivência na formação inicial e continuada do professor quando constituída num espaço relacional, considerando os elementos afetivos e emocionais, favorece a aquisição de conhecimentos e a constituição da personalidade. Esse fato implica uma nova práxis. Essa ação pode potencializar a ação docente, inibindo a reprodução de uma educação tradicional que privilegia a razão em detrimento da emoção (MASETTO, 2003; TARDIF, 2002).

Este estudo vem destacando a importância das vivências psicocorporais por meio de atividades que sejam permeadas pelo corpo, pela corporeidade, pelo brincar, pela brincadeira e ludicidade, para que os professores envolvidos na formação, assim como seus alunos, aprendam brincando. Com isso, os educadores podem perceber a potências das experiências mediadas pelo corpo, ressignificando suas práticas docentes. $\mathrm{Na}$ sequência, um relato de uma professora que se articula com esse pensamento:

Portanto, ao iniciar as atividades de estranhamento, "porque não brincar?", "nós adultos esquecemos que um dia também fomos crianças.", e também "brincar com o outro que não conhecemos?", a proposta de trabalho contribui para nosso aprendizado e o da criança, permite o trabalho lúdico que consequentemente as crianças gostam e sentem prazer ficam envolvidas, traz significado, cativa e fortalece os laços afetivos com o educador, propiciando expressar, sentir, gesticular, falar, vivenciar, experimentar, ampliando assim o conhecimento de si mesmo mundo ao seu redor(P.27). 
O registro do estudo contribuiu com importantes argumentos para a reflexão da formação dos professores da Educação Infantil. Em consonância com a articulação das práticas psicocorporais, constatamos que ninguém gosta do desprazer. Então, ficou evidente que os professores desejam que as formações pela via corporal estejam (sejam) presentes nos espaços formativos. Sendo assim, precisamos estar dispostos a realizar práticas psicocorporais construídas e fortalecidas nas formações — as quais, além de serem marcadas pelas vivências experienciais, precisam ser permanentes na constituição educadora.

\section{Considerações finais}

Notabilizar a linguagem e a expressão corporal nos processos formativos de professores, em especial os que atuam na Educação Infantil, é imprescindível para provocarmos a reflexão sobre as práticas docentes. O refletir sobre a práxis deve ser uma constante no exercício docente. Contudo, ele será potencializado se na formação desses profissionais promovermos atividades que contemplem as emoções. O processo se faz mais expressivo se for mediado pelas narrativas que envolvem as atividades psicocorporais.

A expressão corporal, por meio de gestos e movimentos, é um meio de comunicarmos nossas emoções. As aprendizagens não têm limites e tampouco fronteiras: pelo contrário, elas se potencializam quando o objeto de ensino ou de estudo atribuir sentido à pessoa que estiver no processo de aprender. Tratando-se de professores, adultos ou crianças, cada um apresenta sua subjetividade, constituindo uma aprendizagem significativa pelas vivências e pelas experiências psicocorporais. Sendo assim, é importante promover, na Educação Infantil, atividades que envolvam movimentos, deslocamentos, brincar, representar, atuar, jogar, criar, inventar, enfim, que envolvam o psicocorporal e colocam os professores em uma condição semelhante à de seu aluno em momentos de aprendizagem. Isso leva o professor a refletir sobre sua prática docente, ressignifica valores, crenças e certezas. Esse foi o objetivo do estudo, e os resultados apontam para a urgência de incluir, nos processos formativos, atividades psicocorporais que mobilizam o corpo, as emoções, e oportunizam aos professores ressignificar sua prática docente. 


\section{Referências}

ARIÈS, P. História social da criança e da família. Rio de Janeiro: Zahar, 1978.

ARIZZA, L; DIAS. V; SOUSA. R.; NUNES. B.; GALIAZZI, M. C.; SCHIMIDT, E. B. Articulações metodológicas da análise textual discursiva com o ATLAS.ti: compreensões de uma comunidade aprendente. In: CONGRESSO IBERO AMERICANO EM INVESTIGAÇÃO QUALITATIVA, 4., 2015, Aracaju. Atas... [S.1.]: CIAIQ, 2015. Disponível em: http://proceedings.ciaiq.org/index.php/ciaiq2015/article/view/273. Acesso em: 06 ago. 2021.

BARBOSA, M. C. S. Culturas infantis: contribuições e reflexões. Revista Diálogo Educacional, Curitiba, v. 14, n. 43, p. 654-667, set./dez. 2014. Disponível em: http://www2.pucpr.br/reol/pb/index.php/dialogo?dd1=14717\&dd99=view\&dd98=pb. Acesso: 06 ago. 2021.

BERSCH, A. A. S.; PISKE, E. L. Linguagem corporal na promoção de resiliência: uma prática educacional com acadêmicos do curso de educação física. Revista Interinstitucional Artes de Educar, Rio de Janeiro, v. 5, n.3, p. 596-611, set./dez. 2019.

BERSCH, A. A. S.; PISKE, E. L.; YUNES, M. A. M.; GARCIA, N. M.; SILVEIRA, S. B. A. B.; PIETRO, Â. T. Programa de formação de educadores sociais na promoção da resiliência profissional. Rio Grande: Ed. da FURG, 2019.

BERSCH, A. A. S.; PISKE, E. L. Psicomotricidade relacional: estratégia de intervenção pedagógica na educação. Itinerarius Reflectionis, v. 16, n. 3, p. 1-18, 18 abr. 2020.

BRASIL. Ministério da Educação. Secretaria de Educação Básica. Diretrizes curriculares nacionais para a educação infantil. Brasília: MEC/SEB, 2010.

BRASIL. Ministério da Educação. Secretaria de Educação Básica. Diretrizes Curriculares Nacionais Gerais da Educação Básica. Brasília: MEC/SEB/DICEI, 2013.

CARVALHO, L.A.; WAGNER, L. A. N.; QUITETE, T. M. C. O corpo e o universo lúdico no desenvolvimento de habilidades essenciais no processo de letramento e alfabetização. Revista Humanas \& Sociais Aplicadas, v. 3, n. 7, p. 69-78, 2013. Disponível em: https://ojs3.perspectivasonline.com.br/humanas_sociais_e_aplicadas/article/view/21/15. Acesso: 06 ago. 2021.

CHARMAZ, K. A construção da teoria fundamentada: guia prático para análise qualitativa. Tradução Joice E. Costa. Porto Alegre: Artmed, 2009.

CORSARO, W. A. Sociologia da Infância.2. ed. Porto Alegre: Artmed, 2011.

ELIAS, N. Sobre os Seres Humanos e suas Emoções: um ensaio sob a perspectiva da sociologia dos processos. In: GEBARA, A.; WOUTERS, C. O Controle das Emocões. João Pessoa: Editora da UFPB, 2009. p. 19-46

ELIAS, N. A Civilização dos Pais. Revista Sociedade e Estado, Brasília, v. 27, n. 3, p. 469-493, set./dez. 2012. 
MOUTINHO, K.; DE CONTI, L. Análise narrativa, construção de sentidos e identidade. Revista Psicologia: Teoria e Pesquisa, v. 32, n. 2, p. 1-8, abr./jun. 2016.

FALKENBACH, A. P. Crianças com crianças na psicomotricidade relacional. Lajeado: UNIVATES, 2005.

FLÔR, D. C.; DURLI, Z. (Orgs.). Educação infantil e formação de professores. Florianópolis: EdUFSC, 2012.

FRANCO, M. A. do R. S. Prática pedagógica e docência: um olhar a partir da epistemologia do conceito. Revista Brasileira de Estudos Pedagógicos, Brasília, v. 97, n. 247,p. 534-551, dez. 2016.

GARCIA, N. M.; BERSCH, Â. A. S. (Orgs.). As múltiplas linguagens na educação das infâncias: experiências de ensino e aprendizagens compartilhadas. Rio Grande: Editora da FURG, 2019. (Coleção Cadernos Pedagógicos da EaD, v. 32). Disponível em: https://sead.furg.br/images/cadernos/pdf/volume-32.pdf. Acesso: 06 ago. 2021.

GLASER, B. G.; STRAUSS A. L. The Discovery of Grounded Theory. Chicago: Aldine, 1967.

JULIANO, A.; BERSCH, Â. A. S. Educação Ambiental e psicomotricidade relacional: relato de uma experiência para estudo. Revista Didática Sistêmica, v. 17, n. 1, p. 224-227, 2016. Disponível em: https://periodicos.furg.br/redsis/article/view/5922. Acesso em: 06 ago. 2021.

JULIANO, A. da C.; BERSCH, A. A. S.; PISKE, E. de L.; GARCIA, N. M.; COUSIN, C. Psicomotricidade relacional na educação infantil: relações de pertencimento e reflexões com a educação ambiental. REMEA - Revista Eletrônica do Mestrado em Educação Ambiental, v. 33, n. 3, p. 198-212, 2016. DOI: 10.14295/remea.v33i3.5832.

LAPIERRE, A.; LAPIERRE, A. $O$ adulto diante da criança de 0 a 3 anos: psicomotricidade relacional e formação da personalidade. Curitiba: EdUFPR; Criar, 2010.

LIMA, T. R.; PISKE, E. L.; BERSCH, A. A. Estratégias cooperativas no contexto de acolhimento institucional: psicomotricidade relacional e massagens para bebês. In: CAVALCANTE, L. I. C. et al. (Org.). Acolbimento institucional de crianças e adolescentes. Curitiba: Juruá, 2018.

MATURANA, R. H.; VARELA, J. F. A árvore do conhecimento: as bases biológicas da compreensão humana.9. ed. Trad. Humberto Mariotti; Lia Diskin; ilustr. Carolina Viale; Eduardo Osorio; Francisco Olivares; Marcelo Maturana Montañez. São Paulo: Palas Athena, 2011.

MASETTO, M. T. Competência pedagógica do professor universitário. São Paulo: Summus, 2003.

MELUCCI, A. O jogo do Eu: a mudança de si em uma sociedade global. São Leopoldo: Ed. da Unisinos, 2004.

MERLEAU-PONTY, M. Fenomenologia da percepção. São Paulo: Martins Fontes, 1994.

NEGRINE, A. Aprendizagem e desenvolvimento infantil: Psicomotricidade: alternativas pedagógicas. Porto Alegre: Ed. Prodil, 1995. 
PISKE, E. L.; BERSCH, A. A. S. Práticas educativas psicocorporais nas infâncias. In: RAMOS, F. B. et al. (Orgs.). Congresso Internacional Educar na(s) Infância(s): possibilidades de aprender e de brincar. Caxias do Sul, RS: EDUCS, 2019.

PISKE, E. L.; FIGUEIREDO, M. X. B.; MARQUES, A. L. Era uma vez: convivência familiar e escolar na Fazendo Arte Escola de Educação Infantil. In: BERSCH, A.; GARCIA, N. (Orgs.). As múltiplas linguagens na educação das infâncias: experiências de ensino e aprendizagens compartilhadas. Rio Grande: Editora da FURG, 2019. Disponível em: https://sead.furg.br/images/cadernos/pdf/volume-32.pdf. Acesso: 06 ago. 2021.

PISKE, E. L.; YUNES, M. A. M.; BERSCH, A. A. S.; PIETRO, A. T. Práticas educativas nas instituições de acolhimento sob o olhar das crianças. Revista Educação Pública, Cuiabá, v. 27 n. 66, p. 905-923, 2018. Disponível em: http://periodicoscientificos.ufmt.br/ojs/index.php/educacaopublica/article/view/3364/p df. Acesso em: 06 ago. 2021.

ROCHA, M. L. da; AGUIAR, K. F. de. Pesquisa-intervenção e a produção de novas análises. Revista Psicologia: ciência e profissão, Brasília, v. 23, n. 4, p. 64-73, dez. 2003.

SANCHEZ, P. A.; MARTINEZ, M. R.; PEÑALVER, I. V. A psicomotricidade na educaşão infantil uma prática preventiva e educativa. Porto Alegre: Artmed, 2003.

SARMENTO, M. J. Imaginário e culturas da infância. 2002. (Texto produzido no âmbito das atividades do Projeto As marcas dos tempos: a interculturalidade nas culturas da infância [Projeto POCTI/CED/2002]).

SARMENTO, M.; GOUVEA, M. C. S. de. Estudos da infância: educação e práticas sociais. Petrópolis, RJ: Vozes, 2009.

STRAUSS, A; CORBIN, J. Bases de la investigación cualitativa. Técnicas y procedimientos para desarrollar la teoría fundamentada. Antioquia: Editorial Universidad de Antioquia, 2012.

SAN MARTÍN, D. Teoría fundamentada y Atlas.Ti: recursos metodológicos para la investigación educativa. Revista Electrónica de Investigación Educativa, v. 16, n. 1, p. 104-122, 2014.

SAYÃO, D. T. Corpo e movimento: alguns desafios para a educação infantil. Revista Eletrônica Zero a Seis, Florianópolis, n. 5, jan./jul. 2002.

TARDIF, M. Saberes docentes e formação profissional Petrópolis: Vozes, 2002.

TARDIF, M.; LESSARD, C. O trabalho docente: elementos para uma teoria da docência como profissão de interações humanas. Petrópolis: Vozes, 2005.

RECEBIDO: $21 / 05 / 2020$

APROVADO: 08/04/2021
RECEIVED: 05/21/2020

APPROVED: 04/08/2021
RECIBIDO: $21 / 05 / 2020$

APROBADO: 08/04/2021 